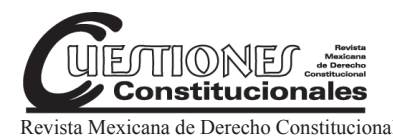

Núm. 37, julio-diciembre 2017

\title{
REFORMA CONSTITUCIONAL O NUEVA CONSTITUCIÓN LA EXPERIENCIA PERUANA
}

\author{
Samuel B. ABAD YUPANQUi*
}

Han pasado más de veinte años y pese a su origen, la Constitución peruana de 1993 sigue vigente. Resulta difícil encontrar una sola respuesta que explique su permanencia. Por un lado, la clase política no ha podido alcanzar un consenso para el cambio: debaten, debaten y debaten; reforma total, Asamblea Constituyente, referéndum, sólo han sido palabras. De otro lado, la ciudadanía no ha interiorizado la relevancia de un cambio constitucional. El "sentimiento constitucional" se ha convertido en una aspiración académica. Otros sectores consideran que el modelo económico que ella introdujo brindó un marco que no se debe revertir, por ello no apuestan por un cambio.

Reconocemos que la actual Constitución no es igual a la de 1993. Por tanto, nos parece relevante recordar sus orígenes y evaluar sus alcances. Luego de más de veinte años y de varios gobiernos distintos, es legítimo preguntarnos ¿cuánto ha aportado la Constitución a la institucionalidad democrática y cuál será el camino a seguir? ¿Ha dado inicio a un nuevo periodo en nuestra historia constitucional?

La Carta de 1993 surgió como un instrumento jurídico y político destinado a legitimar el golpe de Estado del 5 de abril de 1992 y para plasmar reglas no previstas por la Constitución de 1979. Ella trató de consolidar al gobierno no democrático y autoritario del ingeniero Alberto Fujimori. Una Constitución a la medida.

A tal conclusión puede llegarse a través del análisis del procedimiento empleado para elaborar el texto constitucional. Y, especialmente, a par-

* Profesor en Derechos constitucionales de la Pontificia Universidad Católica del Perú. 
Esta revista forma parte del acervo de la Biblioteca Jurídica Virtual del Instituto de Investigaciones Jurídicas de la UNAM

tir del examen de las instituciones plasmadas en él como: el fortalecimiento del Poder Ejecutivo, la introducción de la reelección presidencial inmediata, el Congreso unicameral, la reducción de atribuciones de los gobiernos locales y regionales, ampliación de la competencia de la justicia militar, la pretendida extensión de la pena de muerte, entre otras.

La ciudadanía no exigió un proceso constituyente ni el nacimiento de una nueva Carta, gran parte de ella estuvo desinformada de los alcances de las normas que estaban siendo aprobadas; tampoco existieron canales efectivos para la discusión e incorporación de sus propuestas. Ello determinó la ausencia de un "clima constituyente". La posibilidad de formar conciencia ciudadana respecto al contenido del texto fue limitada.

La forma cómo se reguló el referéndum, realizado el 31 de octubre de 1993, y el modo en que se condujo la campaña electoral estuvieron destinados a favorecer al gobierno. El principio de neutralidad fue vulnerado. Ello, además, contribuyó a una marcada polarización entre quienes estaban a favor de la propuesta oficial y quienes - desde distintos sectores e ideologías - la cuestionaban.

En la actualidad, la versión original del texto constitucional presenta cambios sustanciales. Se ha eliminado la reelección presidencial inmediata, se ha diseñado el marco constitucional básico de la descentralización, se ha incrementado el número de congresistas, entre otras reformas. Además, el aporte del Tribunal Constitucional ha sido fundamental. En el balance, al margen de algunas decisiones cuestionables, ha ido precisando y dotando de contenido a diversas disposiciones constitucionales.

En las líneas que siguen pretendemos evaluar la posibilidad de avanzar a una reforma sustancial del texto constitucional. En Perú, sigue siendo un tema pendiente proceder a una reforma del Estado que garantice a las personas la plena vigencia de sus derechos y una efectiva separación de poderes. Un componente importante es la reforma constitucional. Y es que una democracia constitucional no sólo requiere una economía estable, sino también una sólida institucionalidad.

\section{LA REFORMA CONSTITUCIONAL PENDIENTE}

La caída del régimen fujimorista abrió un escenario propicio para un cambio constitucional que nos hubiera permitido contar con un texto legítimo y de consenso orientado a afianzar la vigencia de los derechos 
Esta revista forma parte del acervo de la Biblioteca Jurídica Virtual del Instituto de Investigaciones Jurídicas de la UNAM

e instituciones constitucionales. En este camino se inscribió el informe presentado en julio de 2001 por la Comisión de Estudio de las Bases de la Reforma Constitucional designada por el presidente Valentín Paniagua. La referida Comisión fue creada a través del Decreto Supremo Núm. 0182001-JUS, publicado el 26 de mayo de 2001, con la finalidad de proponer las normas constitucionales que podrían ser reformadas, las opciones sobre el contenido de las reformas y el procedimiento a seguir para desarrollar las normas constitucionales propuestas. En su primer considerando el Decreto recordaba que la Constitución de 1993: "Fue elaborada y debatida en un escenario de crisis política producto de la interrupción del orden constitucional, y ratificada por un referéndum cuestionado por las irregularidades cometidas en su desarrollo". La Resolución Ministerial Núm. 232-2001-JUS, publicada el 01 de junio, designó a sus veintiocho integrantes.

El Informe de la Comisión planteó tres alternativas posibles para el cambio. La primera proponía el retorno a la Constitución de 1979 y la nulidad de la de 1993, manteniendo vigentes las nuevas instituciones - por ejemplo, la Defensoría del Pueblo - y convocando a una Asamblea Constituyente para que actualizara e incorporara los cambios necesarios a dicha Constitución. La segunda manifestaba la reforma total de la Constitución bajo el procedimiento previsto por la Carta de 1993, incorporando el texto de 1979 con las actualizaciones necesarias. La última propuso aprobar una ley de referéndum que consultara a la ciudadanía si deseaba retornar a la Carta de 1979 y si fuera así convocar a una Asamblea Constituyente para reformarla y actualizarla. También se planteó aprobar una ley de referéndum para que la ciudadanía decida si quiere una nueva Constitución; de suceder ello, se convocaría a una Asamblea Constituyente.

En diciembre de 2001, el Congreso mediante la Ley 27600 optó por una vía distinta. Propuso la "reforma total" de la Constitución por parte del Congreso, lo que motivó que se presentara una demanda de inconstitucionalidad contra ella, la cual finalmente fue desestimada (Exp. 014-2002-AI/TC). Asimismo, dispuso someter el texto aprobado a referéndum. Dicha ley, además, suprimió la firma de Alberto Fujimori de la Constitución de 1993.

De esta manera, se encargó la conducción de la elaboración de la nueva Constitución a la Comisión de Constitución, Reglamento y Acusaciones Constitucionales, presidida por el entonces congresista Henry Pease. 
Esta revista forma parte del acervo de la Biblioteca Jurídica Virtual del Instituto de Investigaciones Jurídicas de la UNAM

Dicha Comisión designó diversos congresistas coordinadores, encargados de abordar una parte de la Constitución, quienes a su vez convocaron a un grupo de personas de la sociedad civil, abogados, expertos, etcétera, para elaborar los textos iniciales.

Esta metodología trajo como consecuencia que inicialmente no existiera una visión de conjunto del texto constitucional, sino que se haya trabajado de manera parcial. Así, por ejemplo, había grupos de trabajo que debían elaborar propuestas sobre derechos de la persona, régimen electoral, régimen económico, gobierno y Congreso, régimen político, administración de justicia, y Estado y nación, las cuales fueron entregadas y sustentadas ante la Comisión de Constitución, Reglamento y Acusaciones Constitucionales.

La Comisión sometió la propuesta a una primera discusión, y luego publicó el anteproyecto, que fue presentado el 5 de abril del 2002 en el Congreso de la República. Dicho texto fue revisado, modificado y aprobado por la Comisión de Constitución dando origen al proyecto de ley de reforma constitucional presentado en julio de 2002 al Pleno del Congreso de la República.

Luego de algunas discrepancias sobre el texto que debería servir de base para la reforma constitucional - el partido aprista propuso volver a la Constitución de 1979 - y de algunas voces que, incluso, cuestionaron la competencia del Congreso de la República para llevar a cabo una reforma total de la Constitución — tema que fue resuelto por el Tribunal Constitucional-, se acordó continuar con el debate del proyecto constitucional. El texto fue aprobado en su gran mayoría en una primera votación. Sin embargo, desde abril de 2003, la reforma quedó paralizada. En efecto, el Congreso acordó suspender el debate constitucional del 25 de abril al 5 de mayo de ese año, pero luego no hubo consenso para retomarlo. Ante la percepción cierta de que la ciudadanía tenía otras prioridades en agenda y el eventual temor a un masivo rechazo en el referéndum, se dejó atrás la vía de una reforma total que requería necesariamente de un referéndum.

Todo ello sucedió pese a que en diciembre de 2003, el Tribunal Constitucional declaró improcedente la acción de inconstitucionalidad interpuesta contra la Carta de 1993 y exhortó al Congreso a que antes de que venciera el mandato de sus miembros — plazo que expiró en julio del 2006- encuentra un camino para la reforma constitucional (Exp. 014-2003-AI/TC), lo cual no llegó a cumplirse. 
Esta revista forma parte del acervo de la Biblioteca Jurídica Virtual del Instituto de Investigaciones Jurídicas de la UNAM

\section{BUSCANDO UN MECANISMO IDÓNEO PARA EL CAMBIO CONSTITUCIONAL}

Después de catorce años de haberse presentado el Informe de la Comisión Paniagua, en julio de 2001, y de apreciar la dificultad de arribar a un consenso parlamentario, el entonces presidente Alejandro Toledo en su mensaje a la Nación —el 28 de julio de 2004 — integró nuevamente el tema de la reforma constitucional en la agenda pública; planteó tres posibles alternativas: reformar la Constitución en las dos siguientes legislaturas ordinarias, optar por conceder facultades constituyentes por espacio de seis meses al Congreso, que empezaría a funcionar en julio de 2006 o convocar a una Asamblea Constituyente elegida por el voto universal, libre y secreto.

Un año después, nuevamente en su discurso del 28 julio, el expresidente Toledo aludió a la necesidad de encontrar una salida definitiva y de consenso al "problema constitucional". En tal ocasión propuso que el próximo Congreso de la República contara con facultades constituyentes durante un año. Esta nueva sugerencia desestimó algunas alternativas que antes había planteado y extendió su propuesta inicial de un "periodo constituyente" del Congreso de seis meses a un año. No obstante, la solución al "problema constitucional" aún carece de una respuesta definitiva.

En efecto, el Congreso, instalado en julio de 2006, no siguió ninguna de las rutas propuestas por las dos fuerzas políticas mayoritarias en sus respectivos planes de gobierno. En ese entonces, el partido aprista señaló que "promoverá que se otorguen facultades constituyentes al nuevo Congreso para restituir la Constitución firmada por Víctor Raúl Haya de la Torre, actualizándola a las necesidades de un Estado promotor, regulador, descentralizado y democrático"; es decir, planteó volver a la Constitución de 1979, adecuándola a la actualidad. Por su parte, el partido nacionalista Unión por el Perú señaló que convocaría a una Asamblea Constituyente que "aprobara la nueva Constitución en un plazo no mayor a doce meses". Sin embargo, no precisó cómo se convocaría a dicha Asamblea.

Para algunos la reforma parcial parece la salida más viable a fin de efectuar los ajustes urgentes y necesarios. Es lo que ha venido sucediendo hasta ahora y lo único a lo que, aparentemente, se puede aspirar. Otros, en cambio, consideran que se requiere de un cambio profundo y por ello, debería convocarse a una Asamblea Constituyente. A nuestro juicio, el país requiere un cambio constitucional en algunos temas sustanciales. 
Esta revista forma parte del acervo de la Biblioteca Jurídica Virtual del Instituto de Investigaciones Jurídicas de la UNAM

Lo que nos parece evidente es que en el Congreso de la República no existe el consenso necesario para hacerlo. En la actualidad, la reforma constitucional es un tema que no aparece en la agenda prioritaria del Congreso; más allá de propuestas puntuales para volver a un régimen bicameral que no han tenido ningún resultado.

Desde un punto de vista teórico existen algunas alternativas que requieren del consenso de las fuerzas políticas para su implementación y del respaldo ciudadano. Por un lado, la Asamblea Constituyente tendría la ventaja de apostar por un nuevo pacto social, ello permitiría contar con un nuevo escenario político y nuevos actores elegidos por el pueblo. Sin embargo, la desventaja es que generaría un duplicidad con el Congreso e incluso hasta podría desplazarlo. Además, dada la fragmentación política del país, no queda claro cuál podría ser el contenido del texto constitucional que se elabore. Muchos podrían ver en ello un riesgo de inestabilidad que pueda cambiar las reglas de juego actualmente existentes.

Desde un punto de vista principista, lo más idóneo hubiera sido volver a la Constitución de 1979, haciéndole los cambios correspondientes que permitan modernizarla y actualizarla, en base a lo dispuesto por el artículo 307 de dicho texto constitucional. Ello, además, hubiera servido para evidenciar que un golpe de Estado - como el del 5 de abril de 1992 - no puede dejar de lado una Constitución legítimamente elaborada. Esta decisión pudo adoptarla el Congreso, luego de la caída del régimen de Fujimori, pero nunca llegó a hacerlo. Después de más de veintiún años de vigencia de la Constitución de 1993, esta alternativa no parece viable.

La Constitución no es un tema exclusivo de abogados. Cualquier decisión por la que se opte — retorno a la Constitución de 1979, reforma parcial o Asamblea Constituyente - debe contar con el máximo consenso posible. Es necesario que exista un "sentimiento constitucional" que haga que la ciudadanía se sienta comprometida con la necesidad de una reforma constitucional que contribuya a afianzar el régimen democrático en el país. Lo más probable es que sólo se admitan reformas puntuales a la Constitución de 1993.

No hay que olvidar que en el Perú un alto porcentaje de la ciudadanía no se siente comprometida con el régimen democrático. En efecto, sólo seis de cada diez ciudadanos consideran que la democracia es preferible a cualquier otra forma de gobierno. ${ }^{*}$ Todo ello puede conducirnos a pen-

* Programa de Naciones Unidas para el Desarrollo, "Perú: la oportunidad de un nuevo ciclo de desarrollo. Escenarios prospectivos 2012-2016", junio de 2012, p. 37. 
Esta revista forma parte del acervo de la Biblioteca Jurídica Virtual del Instituto de Investigaciones Jurídicas de la UNAM

sar que la Constitución no es un elemento de especial relevancia para un sector importante de la ciudadanía a diferencia de países con democracias consolidadas.

En España, por ejemplo, en diciembre de 2003 se conmemoró con gran entusiasmo el 25 aniversario de su Constitución. En México, existe un programa liderado por el Instituto de Investigaciones Jurídicas de la Universidad Nacional Autónoma de México, que viene promoviendo diversas actividades con motivo del cumplimiento de los cien años de vigencia de la Constitución de 1917. En el Perú, nadie festejaría un aniversario de la Carta de 1993, cuando cumplió veinte años sólo se efectuaron publicaciones académicas como ensayos críticos.

En definitiva, el cambio constitucional requiere de un acuerdo entre todas las fuerzas políticas que tome en cuenta los intereses de la población. Sólo así existirá un verdadero "clima constituyente" y encontraremos una salida constitucional duradera y legítima. Por lo demás no debe pensarse que una Constitución resolverá por sí misma los problemas que afronta el país. La reforma constitucional es muy importante pero no es suficiente. Se requiere, además, un cambio en nuestra clase política que le dé la cuota de legitimidad requerida para liderar un cambio y fortalecer nuestra institucionalidad democrática que todavía se encuentra debilitada. 